\title{
La metalurgia del bronce en los Andes Sur Centrales: Tiwanaku y San Pedro de Atacama
}

Heather N. Lechtman ${ }^{1}$ y Andrew W. Macfarlane ${ }^{2}$

\begin{abstract}
RESUMEN
Este estudio es parte de una investigación mayor acerca del desarrollo de la metalurgia del bronce en las áreas central y centro sur de los Andes durante el Horizonte Medio. Se concentra en los tipos de aleación de bronce producidos y diseminados a través de la zona que se ubica aproximadamente entre Tiwanaku y San Pedro de Atacama. Los análisis de isótopo de plomo de los artefactos de bronce excavados en estos dos lugares y de las muestras de un amplio rango de menas metálicas provenientes de depósitos de Bolivia y del norte de Chile indican que los minerales de origen para la mayoría de estos artefactos estuvieron ubicados y fueron explotados en la puna y la sierra alta de Bolivia. Estos resultados nos hacen preguntarnos acerca del movimiento de menas, de lingotes de bronce y de objetos de bronce en el ámbito de la esfera de interacción del centro sur andino durante el Horizonte Medio.
\end{abstract}

Palabras claves: aleaciones de bronce - fuentes de menas metálicas - Horizonte Medio - análisis de isótopo de plomo.

\section{ABSTRACT}

This study is part of a larger investigation into the development of bronze metallurgy in the central and southcentral Andes during the Middle Horizon. It focuses on the kinds of bronze alloy produced and disseminated throughout the region that lies roughly between Tiwanaku and San Pedro de Atacama. Lead isotope analysis of bronze artifacts excavated at these two places and of a wide range of metallic ores sampled from deposits in Bolivia and Northern Chile indicates that the ore sources for most of the artifacts were located and exploited in the puna and high sierra of Bolivia. These results raise questions about the movement of ore, of bronze lingots, and of bronze objects within the south-central Andean interaction sphere during the Middle Horizon.

Key words: bronze alloys - metallic ore sources - Middle Horizon - lead isotope analysis.

Recibido: enero 2005. Aceptado: julio 2005.

1 Center for Materials Research in Archaeology and Ethnology, Massachusetts Institute of Technology, Room 8-437, Cambridge MA 02139, ESTADOS UNIDOS. Email: lechtman@mit.edu

\section{Introducción}

El desarrollo y uso del bronce en el Area Andina fue un fenómeno del Horizonte Medio. La difundida explotación de menas complejas de cobre, arsénico, estaño y níquel y la producción por vez primera de un rango de bronces a gran escala durante este período, tal vez constituyen una marca tecnológica distintiva de dicho Horizonte.

¿Qué significa el término "bronce" y cómo se puede hablar de un "rango de bronces"? Los bronces son aleaciones de cobre con otros metales. Estas aleaciones comparten ciertas propiedades físicas o mecánicas. El "bronce clásico" es la aleación de cobre con estaño y en los Andes se acostumbra asociar el bronce estañífero con el Imperio incaico. Ahora sabemos que el bronce estañífero fue producido mucho más temprano, durante el Horizonte Medio.

Además, existen otras aleaciones que son verdaderos bronces: por ejemplo la aleación binaria compuesta de dos metales -cobre y arsénico- llamada "bronce arsenical" y una aleación ternaria y bastante rara, compuesta de tres metales -cobre, arsénico y níquel (Lechtman 1996, 1997, 1999, 2003a, 2003b).

Se ha demostrado en el laboratorio que existe poca diferencia en cuanto a las propiedades mecánicas entre estas tres aleaciones de bronce. Como metales, funcionan de manera similar. Con respecto a sus características, difieren principalmente en su ductilidad y color (Lechtman 1996).

\section{Los bronces y sus menas}

Durante el Horizonte Medio, en toda la zona de los Andes Centrales, es decir, en el territorio que

2 Department of Earth Sciences, PC 314, Florida International University, 11200 SW 8th Street, University Park, Miami FL 33199, ESTADOS UNIDOS. Email: macfarla@fiu.edu 
actualmente corresponde a Perú y a Ecuador, solamente se produjo bronce arsenical. También es la zona con la cual asociamos la influencia Wari durante dicho período (Figura 1). El lago Titicaca constituyó el límite meridional para la producción de este bronce en gran escala.

Hay una relación impresionante entre la zona donde se produjeron objetos de bronce arsenical y las menas que existen en gran abundancia en la misma zona. Estas menas contienen ambos, cobre y arsénico, en la estructura de sus minerales metálicos (Tabla 1). Las fuentes primarias de arsénico para los bronces arsenicales andinos son menas como enargita (un sulfuro) y sus productos de alteración como los óxidos chenevixita o olivenita. $\mathrm{La}$ arsenopirita es otra mena que pudo aportar el arsénico utilizado en los bronces producidos en el extremo norte de la costa peruana.

El mapa de la Figura 2 indica donde se ubican los principales depósitos de menas de enargita en la zona andina. Menas de enargita existen en una faja que se extiende desde Pilzhum en el sur de Ecuador hasta Laurani en el norte de Bolivia y al noroeste de Argentina. Los depósitos más grandes y más ricos que son depósitos macizos se localizan en el Perú central.

El mapa aclara porque los arqueólogos encuentran una gran concentración de artefactos de bronce arsenical en la zona andina central (ver p.e., Figuras 3 a 6). Allí existen abundantes y accesibles depósitos muy ricos de enargita y de sus productos de alteración. Los mineros de toda la zona central pudieron haber explotado fácilmente estos ricos depósitos. Con la fundición de estas menas se producen directamente aleaciones de cobre-arsénico, es decir, bronce arsenical, dentro del horno. En los Andes Centrales no se encontraron objetos hechos de bronce estañífero antes del Imperio incaico.

¿Cuál es la situación respecto del bronce estañifero? Las poblaciones que habitaron el altiplano boliviano y las tierras altas del Noroeste Argentino durante el Horizonte Medio explotaron los ricos depósitos de casiterita -óxido de estaño- localizados en el extremo sur de Perú (en la orilla oriental del lago Titicaca), en el norte de Bolivia y en el noroeste de Argentina. Los campos de estaño bolivianos y argentinos indicados en la Figura 2 constituyen la única fuente significativa de estaño de los Andes y son uno de los depósitos de casiterita más ricos del mundo. Ellos abastecieron el estaño necesario para la producción de bronce estañífero durante los períodos Horizonte Medio, Intermedio Tardío y Horizonte Tardío (ver p.e., Figuras 7 y 8 ).

\section{El bronce ternario: Tiwanaku y San Pedro de Atacama}

Al sur del lago Titicaca, en el altiplano boliviano y en el norte de Chile, para el mismo período existen evidencias recientemente obtenidas de la producción de un tercer tipo de bronce: una aleación ternaria compuesta de cobre, arsénico y níquel (Lechtman 1997, 1998, 1999, 2003a, 2003b). En ciertos aspectos, esta aleación ternaria es la más interesante de los tres tipos de bronce. Es intrigante en primer lugar porqué este tipo de bronce es extremadamente raro, no sólo en los Andes sino en cualquier otra parte del mundo antiguo.

Segundo, las menas de níquel son casi inexistentes en los Andes (Tabla 2).

\begin{tabular}{|lll|}
\hline MENAS DE COBRE & & \\
\hline Metal nativo & Domeykita & $\mathrm{Cu}_{3} \mathrm{As}$ \\
Sulfuro & Enargita & $\mathrm{Cu}_{3} \mathrm{AsS}_{4}$ \\
& Tennantita & {$\left[\left(\mathrm{Cu}_{2} \mathrm{Fe}_{12} \mathrm{As}_{4} \mathrm{~S}_{13}\right]\right.$} \\
Oxido & Olivenita & {$\left[\mathrm{Cu}_{2}\left(\mathrm{AsO}_{4}\right)(\mathrm{OH})\right]$} \\
& Chenevixita & {$\left[\mathrm{Cu}_{2}\left(\mathrm{AsO}_{4}\right)_{2}(\mathrm{OH})_{4} \cdot \mathrm{H}_{2} \mathrm{O}\right]$} \\
\hline MENAS DE FIERRO & & \\
\hline Sulfuro & Arsenopyrita & $\mathrm{FeAsS}$ \\
Oxido & Scorodita & $\mathrm{FeAsO}_{4} \cdot 2 \mathrm{H}_{2} \mathrm{O}$ \\
\hline
\end{tabular}

Tabla 1. Menas comunes que contienen arsénico. 


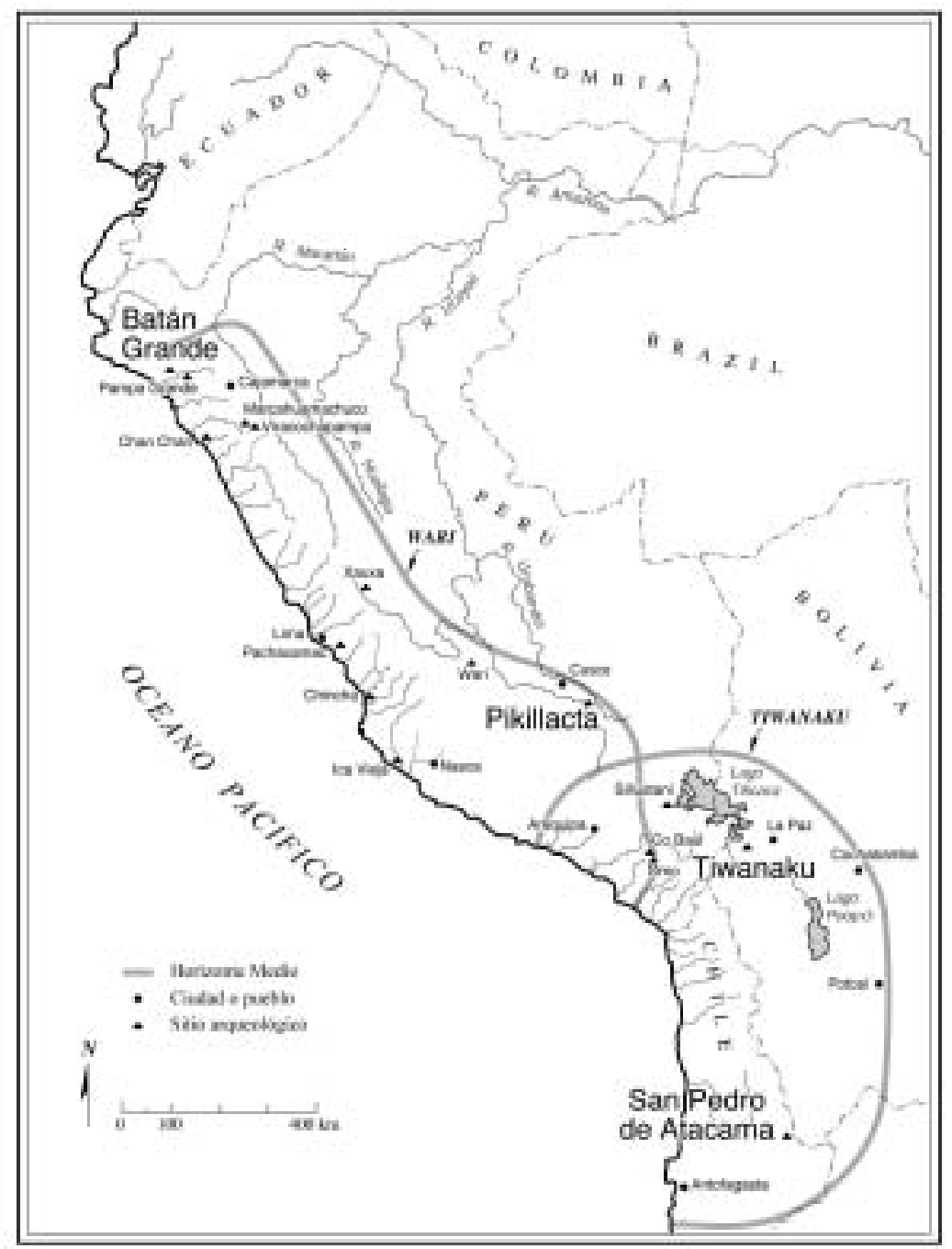

Figura 1. Mapa de la región de los Andes Centrales y Sur Centrales, mostrando las esferas de influencia Wari y Tiwanaku durante el Horizonte Medio (cortesía de W. Isbell).

En la tierra, el níquel se encuentra mayormente en el manto, la capa que está debajo de la corteza que forma la superficie de la tierra. En algunos minerales como el silicato olivino que abunda en el manto hay níquel. Para que se formen depósitos de níquel económicamente aprovechables, en general, es necesario que los materiales derivados del manto vengan expuestos en la corteza a la superficie de la tierra. Virtualmente todas las modernas minas de níquel en el mundo están asociadas con rocas que se formaron en su mayoría a partir de materiales del manto, como las rocas volcánicas marinas o las rocas derivadas de la fusión del manto a consecuencia de antiguos impactos de meteoritos. Típicamente estas menas contienen minerales sulfúreos que llevan níquel o los productos del intemperismo del olivino con contenido de níquel. En la región andina, la corteza es extraordinariamente potente (en algunos lugares más de $60 \mathrm{~km}$ ) y las rocas que provienen en su mayoría del manto subyacente son raras.

En consecuencia, los minerales de níquel son muy escasos en la zona andina. El mapa de la Figura 2 muestra la distribución de los depósitos de níquel en la región considerada. La mayoría de los depósitos peruanos están ubicados en la vertiente oriental andina, son pequeños, de difícil acceso y de muy baja ley. Los depósitos de níquel en las tierras altas de Bolivia, el Noroeste Argentino y la costa central de Chile son más accesibles, pero también son pequeños y tienen una distribución 


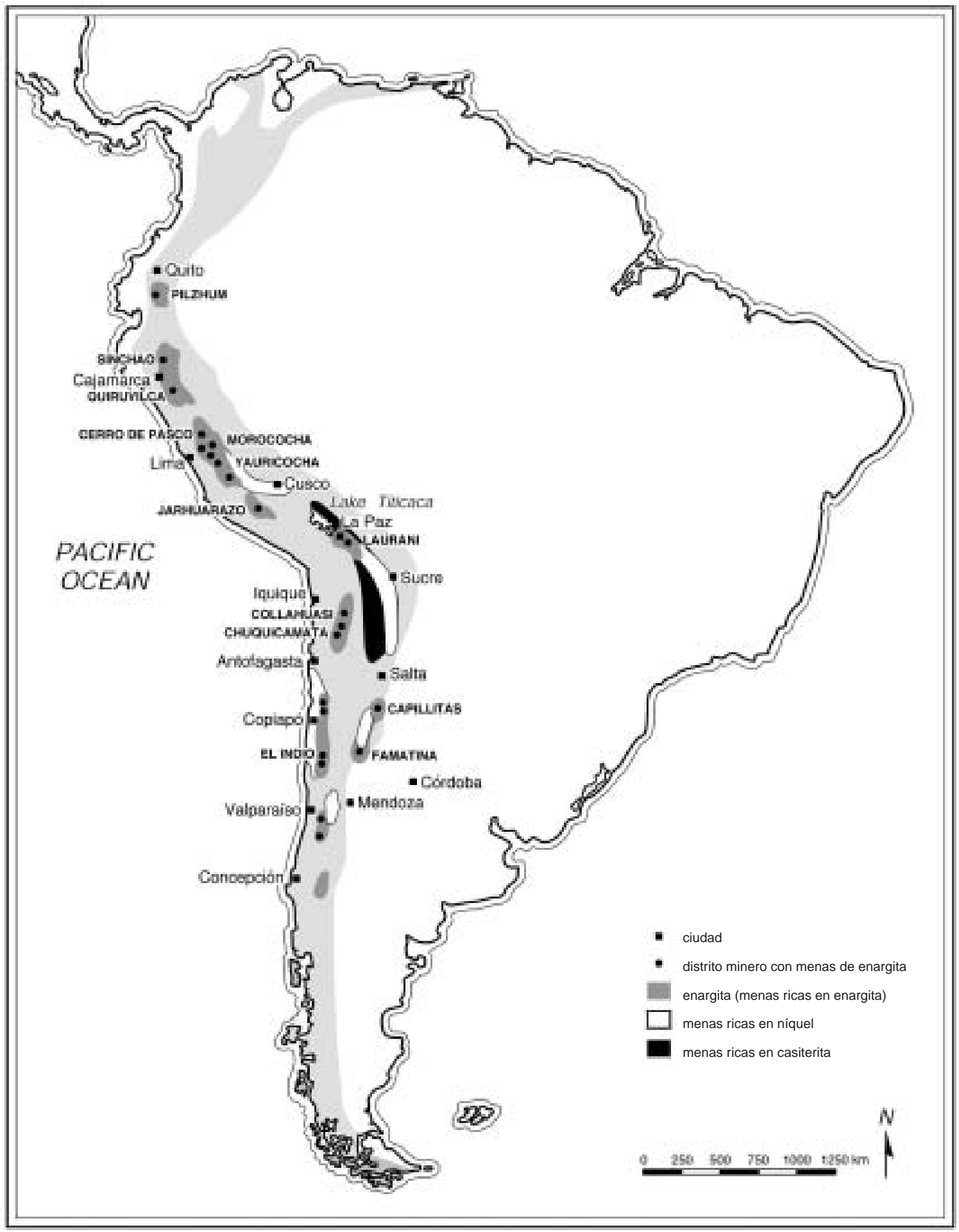

Figura 2. Mapa donde se muestra la ubicación de los principales depósitos de menas de enargita, de níquel y de casiterita en la zona andina de Sudamérica (tomado de Lechtman 2003b). 


\begin{tabular}{|ll|}
\hline Niquelina & $\mathrm{NiAs}$ \\
\hline Gersdorffita & $\mathrm{NiAsS}$ \\
\hline $\begin{array}{l}\text { Compuestos: domeykita- } \\
\text { rammelsbergita-niquelina }\end{array}$ & $\mathrm{Cu}_{3} \mathrm{As}-\mathrm{NiAs}_{2}$-NiAs \\
\hline
\end{tabular}

Tabla 2. Minerales metálicos que contienen níquel y arsénico.

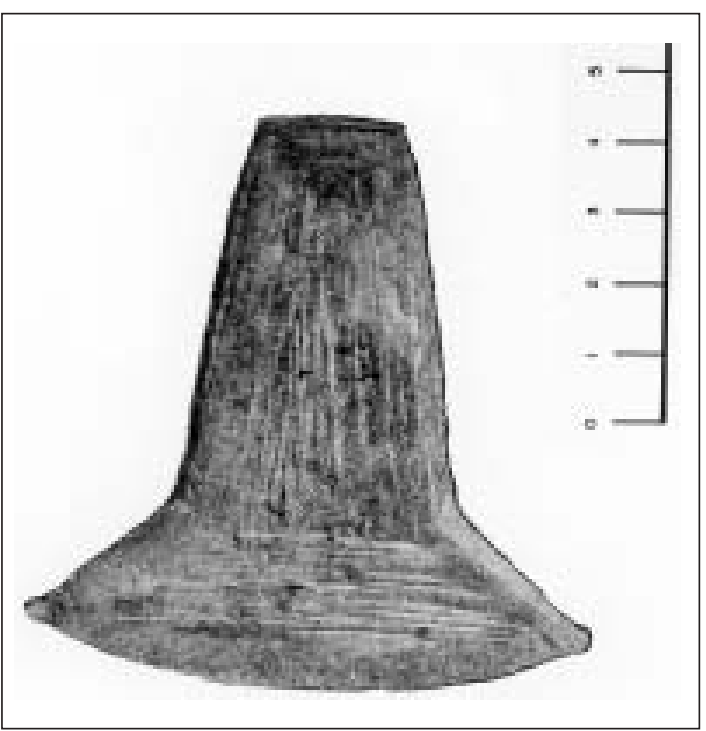

Figura 3. Hacha-moneda, proveniente de Ecuador, martillada en bronce arsenical. Colección del Museo Antropológico del Banco Central, Guayaquil, Ecuador.

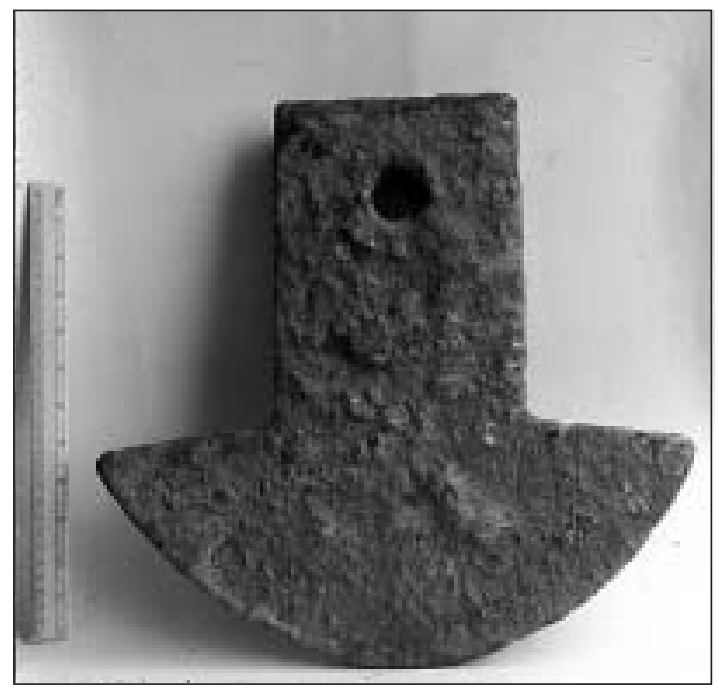

Figura 4. Hacha gigante, proveniente de Ecuador. Vaciada en bronce arsenical. Colección del Museo de Arte Prehistórico, Casa de la Cultura, Guayaquil, Ecuador.
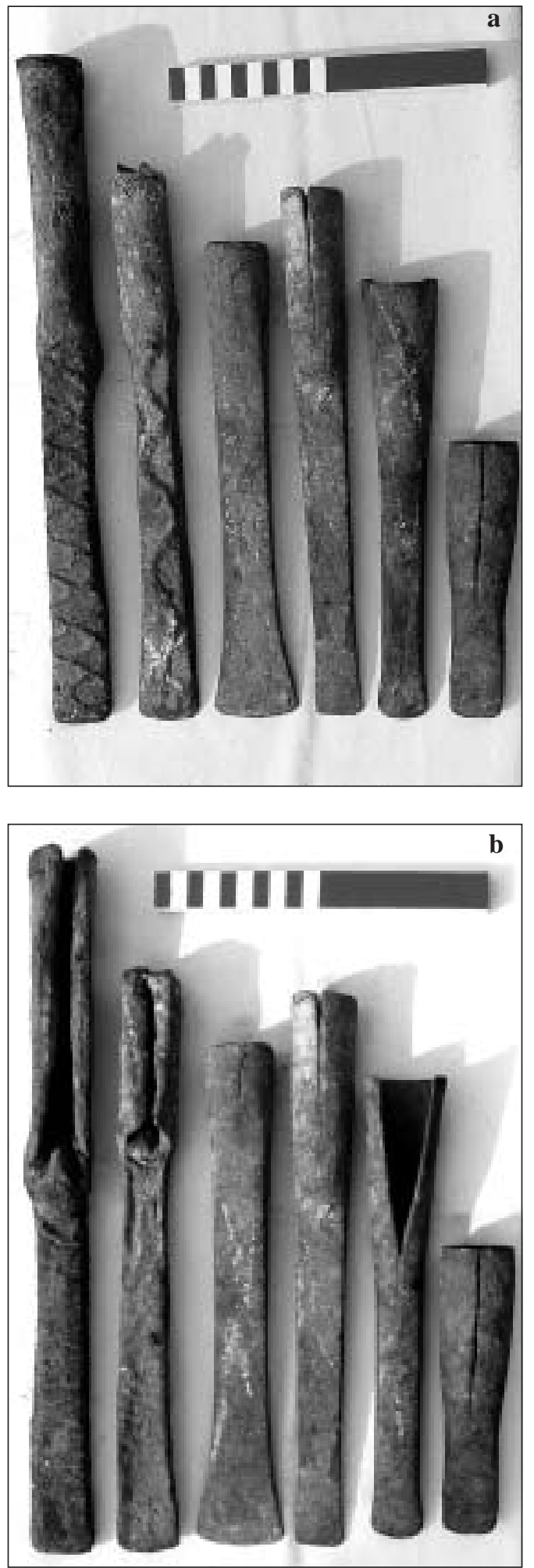

Figuras 5a y 5b. Las llamadas "puntas", cuya función es desconocida. Provienen del valle de Lambayeque, costa norte del Perú, y fueron vaciadas y martilladas en bronce arsenical (5a, anterior; 5b, posterior). Colección del Museo Brüning, Lambayeque, Perú. 


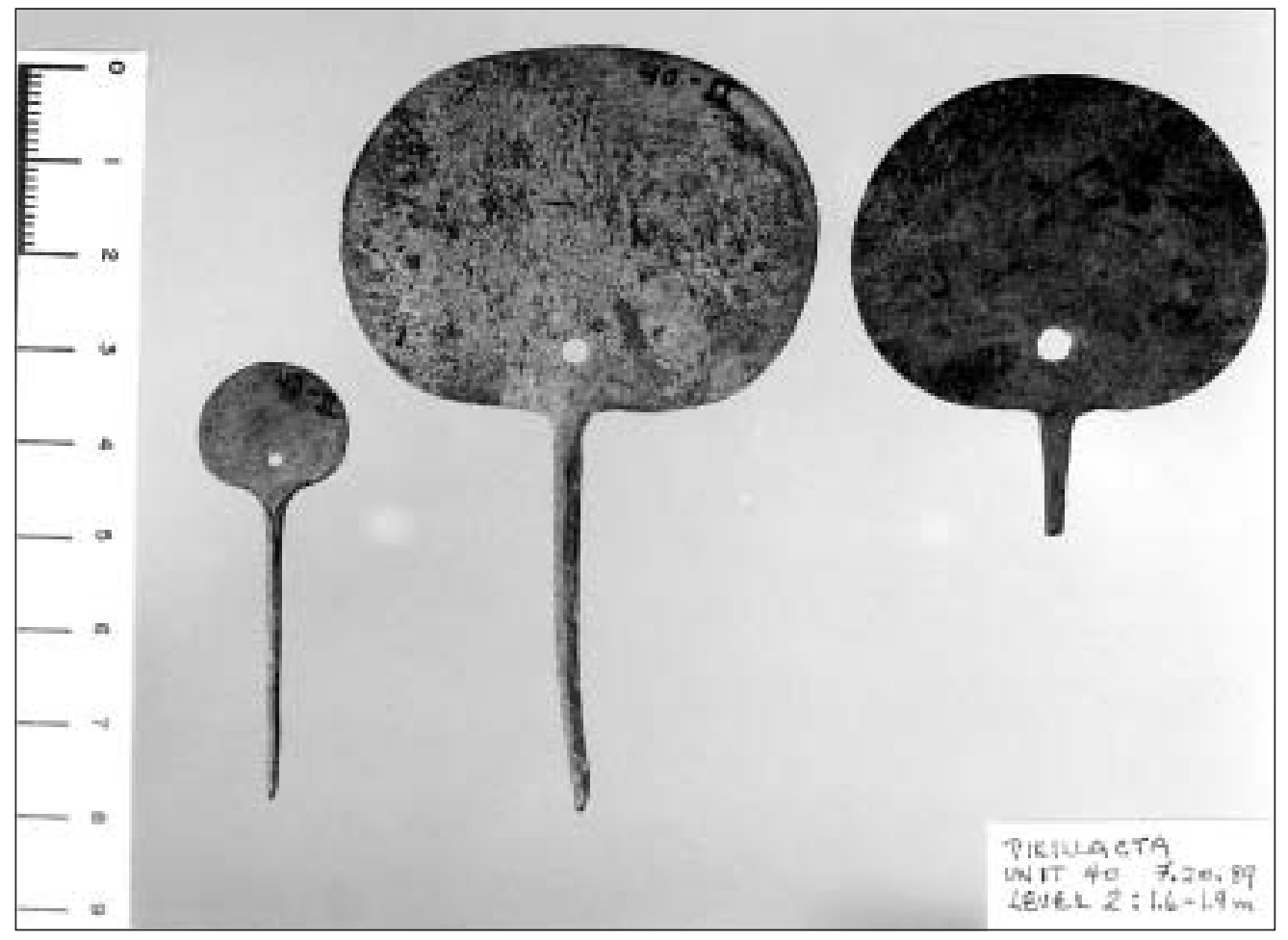

Figura 6. Tupus, excavados en Pikillacta, Perú. Martillados en bronce arsenical. Colección del Museo de la Casa Garcilaso, Cusco, Perú.

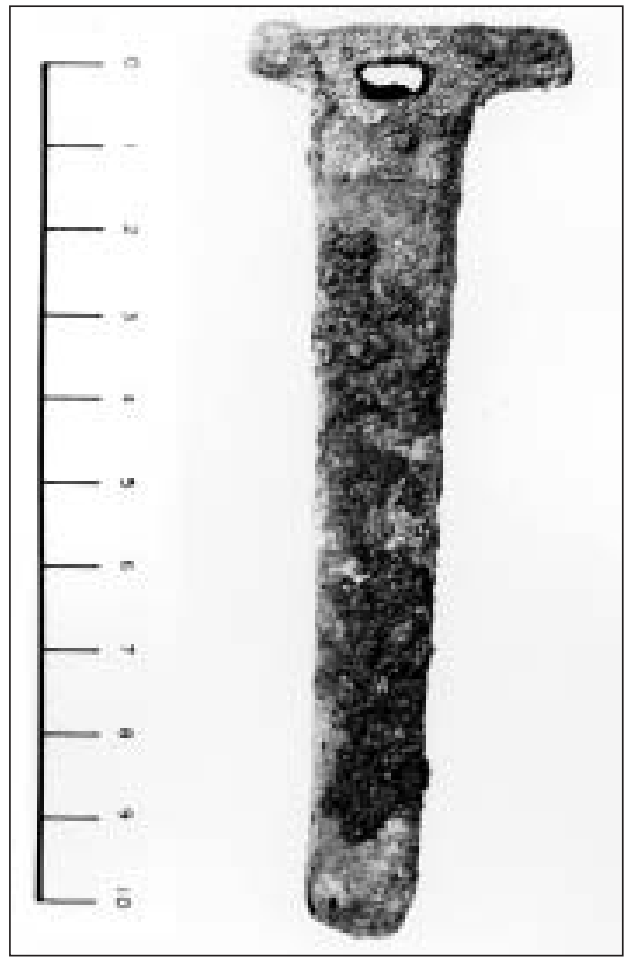

Figura 7. Hacha ' $T$ ' con cuerpo grueso, excavada en Lukurmata, Bolivia. Vaciada en bronce estañífero. Colección del Museo Arqueológico, Tiwanaku, Bolivia.

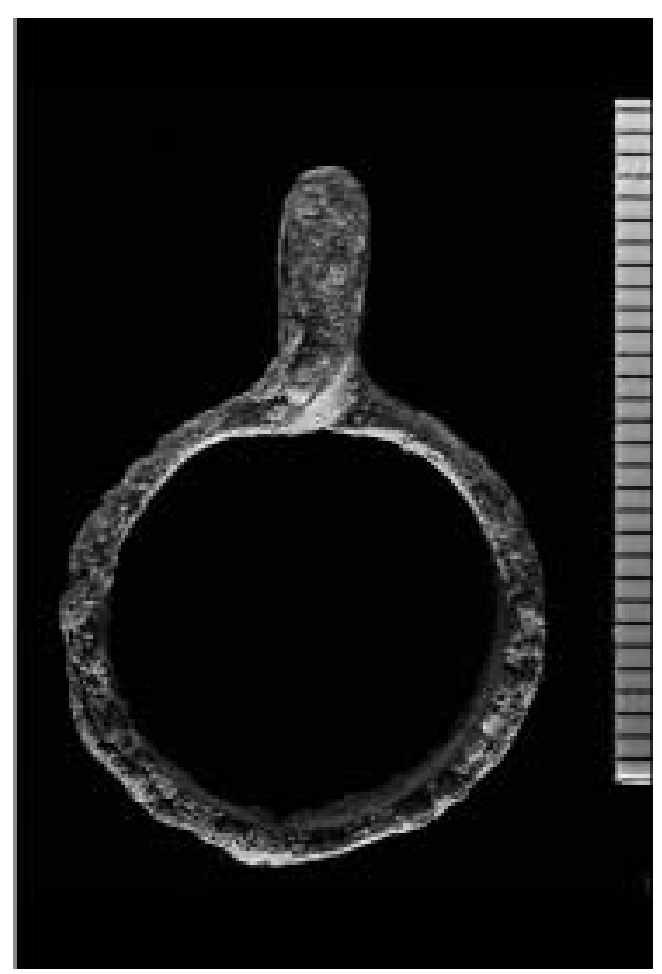

Figura 8. Anillo, excavado en Tiwanaku, Bolivia. Martillado en bronce estañífero. Colección del Museo Arqueológico, Tiwanaku, Bolivia. 
esporádica siendo también muy pobres. De hecho, hasta ahora no hemos ubicado la fuente o las fuentes de mineralización de níquel que pudieron haber sido usadas en la producción del bronce ternario.

Hay una tercera razón que justifica nuestro interés especial en el bronce ternario. Hasta ahora los arqueólogos han excavado objetos metálicos fabricados con este extraño bronce solamente en dos lugares de los Andes: Tiwanaku y San Pedro de Atacama.

Si consideramos la situación de Tiwanaku durante el Horizonte Medio, vemos que la mitad (50\%) de los artefactos excavados de cobre o de bronce procedentes de la cuenca del Titicaca y analizados en nuestros laboratorios está hecha con bronce ternario (ver p.e., Figuras 9 a 12). La Tabla 3 indica que durante el Formativo Tardío el $80 \%$ de todos estos artefactos fue fabricado con el bronce ternario. Durante el apogeo de la influencia Tiwanaku, la situación cambió poco a poco con la introducción del bronce estañífero, pero la mayoría de los artefactos siguió siendo producida con bronce ternario. El bronce estañífero reemplazó casi completamente al bronce ternario de cobre-arsénico-níquel solamente en la época tardía de Tiwanaku (Lechtman 1997, 1999, 2003a).

Como tenemos artefactos de bronce ternario de Tiwanaku y de San Pedro, es necesario hacer una comparación entre los dos conjuntos. A la fecha hemos examinado y analizado (Tabla 4) el $80 \%$ de todas las hachas que existen en las colecciones del Museo Arqueológico R. P. Gustavo Le Paige en San Pedro de Atacama (Figura 13). De este grupo (36 en total) el $61 \%$ de las hachas están hechas con bronce ternario, el resto están fabricadas mayormente con bronce estañífero. En San Pedro no tenemos el mismo nivel de control respecto a la cronología del conjunto como sí se tiene con los artefactos excavados recientemente en Tiwanaku. Sin embargo, la evidencia presentada en la Tabla 5, proporcionada por Myriam Tarragó y Agustín Llagostera (com. pers., 2003-2004), muestra claramente la pertenencia de muchas hachas al Horizonte Medio.

La rareza del bronce ternario provocó una serie de interrogantes sobre las posibles relaciones entre el acceso al material y su uso en Tiwanaku y en San Pedro de Atacama: 1) ¿la aleación fue producida en ambos lugares?; 2) ¿fue producida solamente en uno de estos lugares y luego importada por el otro?; 3) ¿es posible que en ambos lugares se haya usado cobre extraído de depósitos locales y cercanos para producir la aleación, pero que se intercambiaron las menas que contribuyeron a la aleación el níquel o el níquel más el arsénico?; y finalmente, 4) ¿en qué etapa de la producción de esta rara aleación el níquel pudo haber sido compartido o intercambiado?, ¿en forma de unas menas ricas en níquel?, ¿en forma de lingotes ya producto de la aleación?, ¿en forma de objetos del bronce ternario ya acabados?

\section{Los análisis isotópicos de plomo de menas provenientes de los Andes Centro Sur}

Hemos buscado las respuestas a estas preguntas utilizando las técnicas de análisis de los isótopos de plomo. El mapa de la Figura 14b muestra la región de los Andes Centro Sur, incluso a

\begin{tabular}{|c|c|c|c|c|c|c|c|c|c|c|c|}
\hline \multirow[b]{3}{*}{$\begin{array}{l}\text { Fase } \\
\text { Tiwanaku }\end{array}$} & \multirow[b]{3}{*}{$\begin{array}{l}\text { Número } \\
\text { analizado }\end{array}$} & \multicolumn{10}{|c|}{ Tipo de aleación } \\
\hline & & \multicolumn{2}{|r|}{$\mathrm{Cu}$} & \multicolumn{2}{|c|}{ Cu-As } & \multicolumn{2}{|c|}{$\mathrm{Cu}-\mathrm{As}-\mathrm{Ni}$} & \multicolumn{2}{|c|}{$\mathrm{Cu}-\mathrm{Sn}$} & \multicolumn{2}{|c|}{$\mathrm{Cu}-\mathrm{As}-\mathrm{Ni}$-Sn } \\
\hline & & $\mathbf{N}^{\circ}$ & $\%$ Total & $\mathbf{N}^{\circ}$ & $\%$ Total & $\mathbf{N}^{\circ}$ & $\%$ Total & $\mathbf{N}^{\circ}$ & $\%$ Total & $\mathbf{N}^{\circ}$ & $\%$ Total \\
\hline $\begin{array}{l}\text { Formativo Tardío 2- } \\
\text { Tiw IV Temprano }\end{array}$ & 11 & - & - & 1 & 9.1 & 9 & 81.8 & 1 & 9.1 & - & - \\
\hline $\begin{array}{l}\text { Tiw IV Tardío - } \\
\text { Tiw V Temprano }\end{array}$ & 11 & 1 & 9.1 & - & - & 6 & 54.6 & 3 & 27.3 & 1 & 9.1 \\
\hline Tiw V & 6 & - & - & - & - & 1 & 16.7 & 5 & 83.3 & - & - \\
\hline Posterior a Tiw & 3 & 1 & 33.3 & - & - & - & - & 2 & 66.6 & - & - \\
\hline
\end{tabular}

Tabla 3. Cronología de aleaciones de bronce de la cuenca del Titicaca (tomado de Lechtman 2003a). 


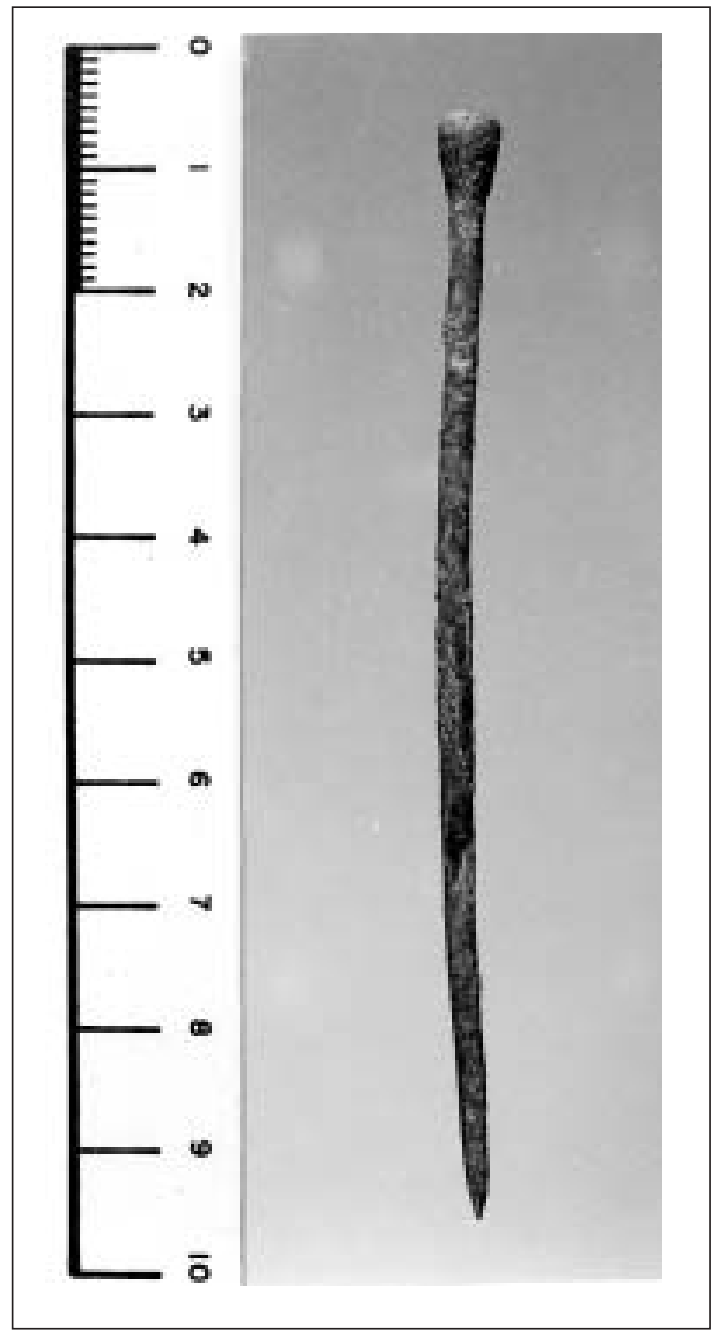

Figura 9. Tupu excavado en Tiwanaku, Bolivia. Martillado en bronce ternario (cobre-arsénico-níquel). Colección del Museo Arqueológico, Tiwanaku, Bolivia.

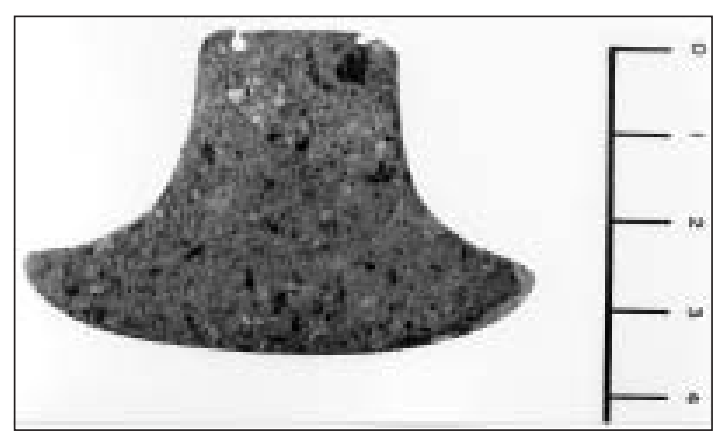

Figura 10. Cuchillo excavado en Tiwanaku, Bolivia. Martillado en bronce ternario (cobre-arsénico-níquel). Colección del Museo Arqueológico, Bolivia.

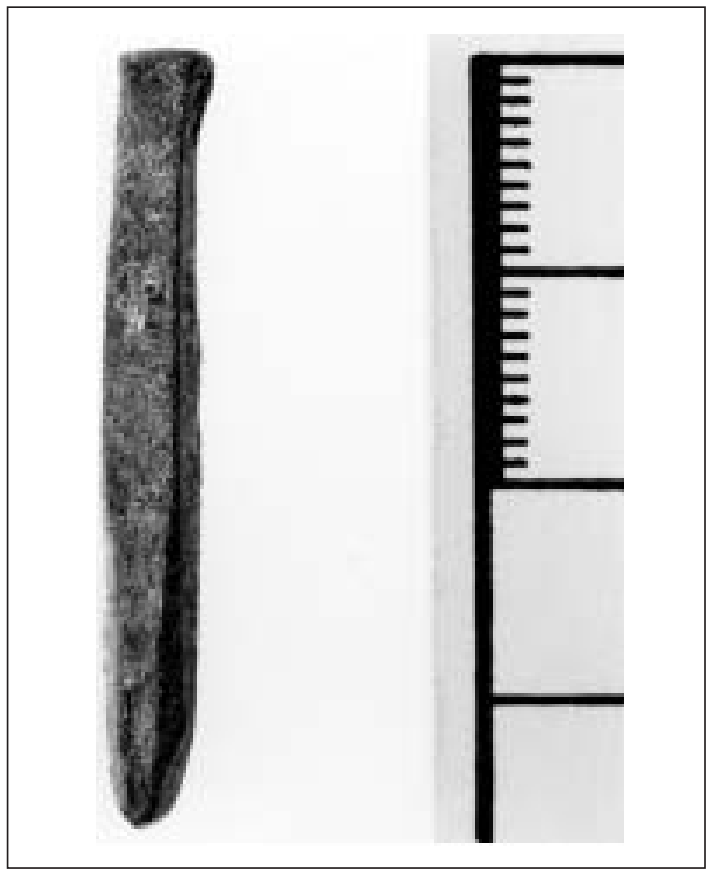

Figura 11. Clavo excavado en Tiwanaku, Bolivia. Martillado en bronce ternario (cobre-arsénico-níquel). Colección del Museo Arqueológico, Tiwanaku, Bolivia.

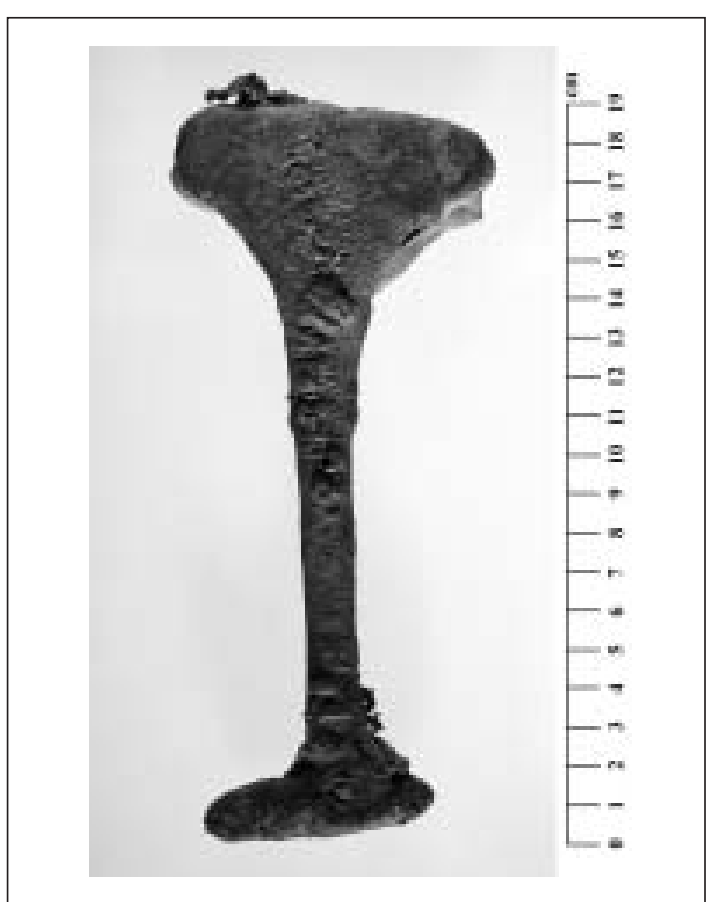

Figura 12. Grapa arquitectónica, excavada del muro del canal sur de la pirámide Pumapunku, Tiwanaku, Bolivia. Se fabricó vertiendo el metal derretido en una cavidad tallada en la cara superior en la unión de piedras adyacentes del muro del canal. Hecha en bronce ternario (cobre-arsénico-níquel). Colección del Museo Arqueológico, Tiwanaku, Bolivia. 
LA METALURGIA DEL BRONCE EN LOS ANDES SUR CENTRALES: TIWANAKU...

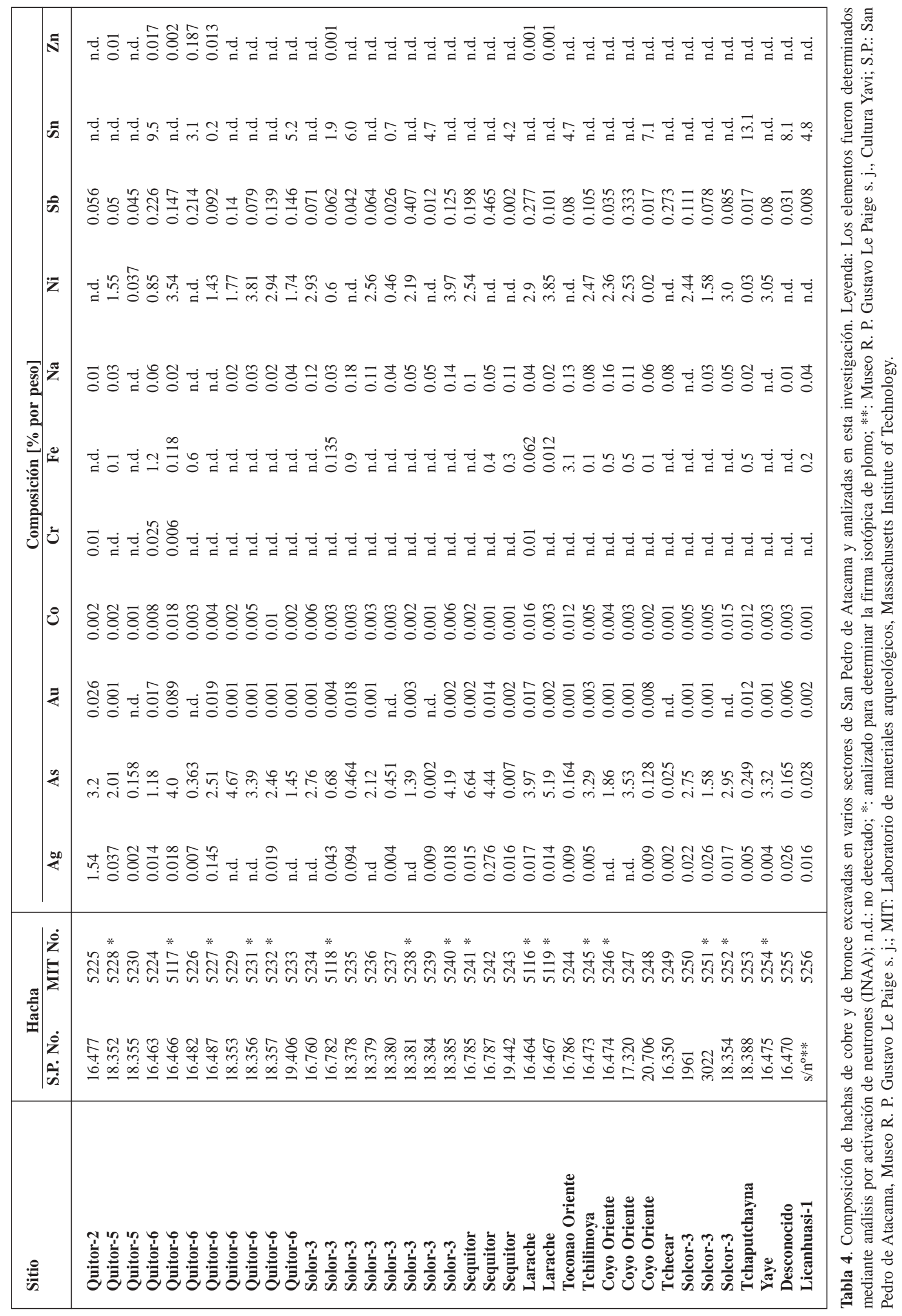


Tiwanaku y a San Pedro de Atacama. Las varias zonas indicadas corresponden a las provincias isotópicas de plomo (Macfarlane et al. 1990). Cuando analizamos rocas y menas ubicadas en el altiplano o en la sierra alta, sus valores isotópicos de plomo caerán en alguna parte dentro del campo llamado Provincia Isotópica III. Cuando analizamos rocas y menas ubicadas en la costa de la región centro-sur, sus valores isotópicos de plomo caerán en alguna parte dentro del campo lla-

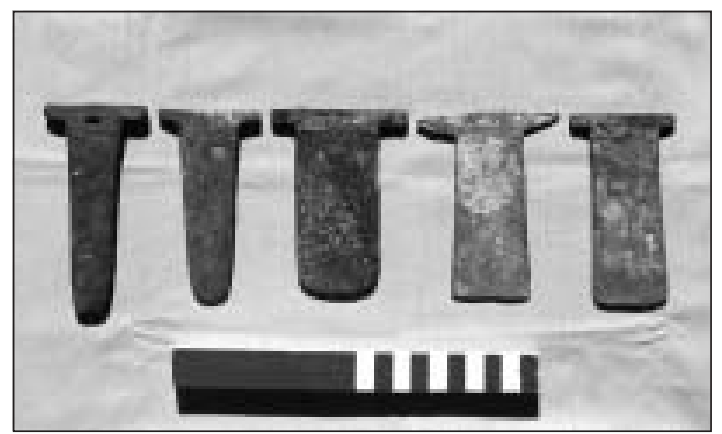

Figura 13. Grupo de hachas ' $T$ ' con cuerpo grueso, excavadas en San Pedro de Atacama, Chile. Vaciadas y martilladas en bronce ternario (cobre-arsénico-níquel). Colección del Museo R. P. Gustavo Le Paige s. j., San Pedro de Atacama, Chile. mado Provincia Isotópica I. Los valores isotópicos de rocas y menas ubicadas en el área intermedia -en las yungas o vertientes occidentales- caerán en alguna parte dentro del campo llamado Provincia Isotópica II.

\section{La Fosa Chile-Perú}

Los valores isotópicos de plomo denominados también las firmas isotópicas de plomo (los términos son sinónimos) de rocas y menas ubicadas a lo largo de la zona andina de Sudamérica varían. La firma isotópica de plomo de una roca o mena varía en función directa de su distancia desde la Fosa Chile-Perú.

La Fosa Chile-Perú marca la frontera geológica entre la placa de Nazca al oeste, que forma el piso oceánico sur-oriental del Océano Pacífico, y la placa sudamericana al este (Figura 15). La convergencia de estas dos placas empuja la placa de Nazca hacia abajo en el manto a lo largo de la orilla occidental del relativamente boyante continente sudamericano. A su vez, la subducción de la placa de Nazca con su cubierta de sedimentos provoca una fusión en el manto debajo

\begin{tabular}{|c|c|c|c|c|}
\hline Sitio & San Pedro ${ }^{\circ}$ & $\operatorname{MIT} n^{\circ}$ & $\begin{array}{l}\text { Asignación } \\
\text { cronológica }\end{array}$ & Comentario \\
\hline Quitor-5 & 18.352 & $5228 *$ & MT, AL & $\begin{array}{l}\text { MT: Tiwanaku (hay como ofrenda algún bien } \\
\text { de esa filiación concreta) }\end{array}$ \\
\hline Quitor-5 & 18.355 & 5230 & MT & $\begin{array}{l}\text { MT: Tiwanaku (hay como ofrenda algún bien } \\
\text { de esa filiación concreta) }\end{array}$ \\
\hline Quitor-6 & 16.463 & 5224 & $\mathrm{AL}$ & \\
\hline Quitor-6 & 16.466 & $5117 *$ & $\mathrm{AL}$ & \\
\hline Quitor-6 & 16.482 & 5226 & MT, AL & $\begin{array}{l}\text { MT: Tiwanaku (hay como ofrenda algún bien } \\
\text { de esa filiación concreta) }\end{array}$ \\
\hline Quitor-6 & 16.487 & 5227 & MT & $\begin{array}{l}\text { MT: Tiwanaku (hay como ofrenda algún bien } \\
\text { de esa filiación concreta) }\end{array}$ \\
\hline Quitor-6 & 18.353 & 5229 & MT, AL & \\
\hline Quitor-6 & 18.356 & $5231 *$ & MT, AL & $\begin{array}{l}\text { MT: Tiwanaku/Aguada (además de bienes } \\
\text { Tiwanaku hay objetos claramente de La } \\
\text { Aguada del Noroeste Argentino) } \\
\text { AL: Transición Temprano/Medio }\end{array}$ \\
\hline Quitor-6 & 18.357 & $5232 *$ & MT, AL & \\
\hline Quitor-6 & 19.406 & 5233 & $\mathrm{AL}$ & \\
\hline Solor-3 & 18.381 & $5238 *$ & MT, AL & \\
\hline Solor-3 & 18.384 & 5239 & MT, AL & \\
\hline Solor-3 & 18.385 & $5240 *$ & MT, AL & \\
\hline Toconao Oriente & 16.786 & 5244 & $\mathrm{AL}$ & \\
\hline Coyo Oriente & 16.474 & 5246 & $\mathrm{AL}$ & \\
\hline Coyo Oriente & 17.320 & 5247 & $\mathrm{AL}$ & \\
\hline Coyo Oriente & 20.706 & 5248 & $\mathrm{AL}$ & \\
\hline
\end{tabular}

Tabla 5. Hachas de San Pedro de Atacama analizadas en esta investigación y procedentes de tumbas cuya cronología corresponde al Horizonte Medio. Leyenda: MT: Myriam Tarragó; AL: Agustín Llagostera; *: Analizado para determinar la firma isotópica de plomo. 
LA METALURGIA DEL BRONCE EN LOS ANDES SUR CENTRALES: TIWANAKU...

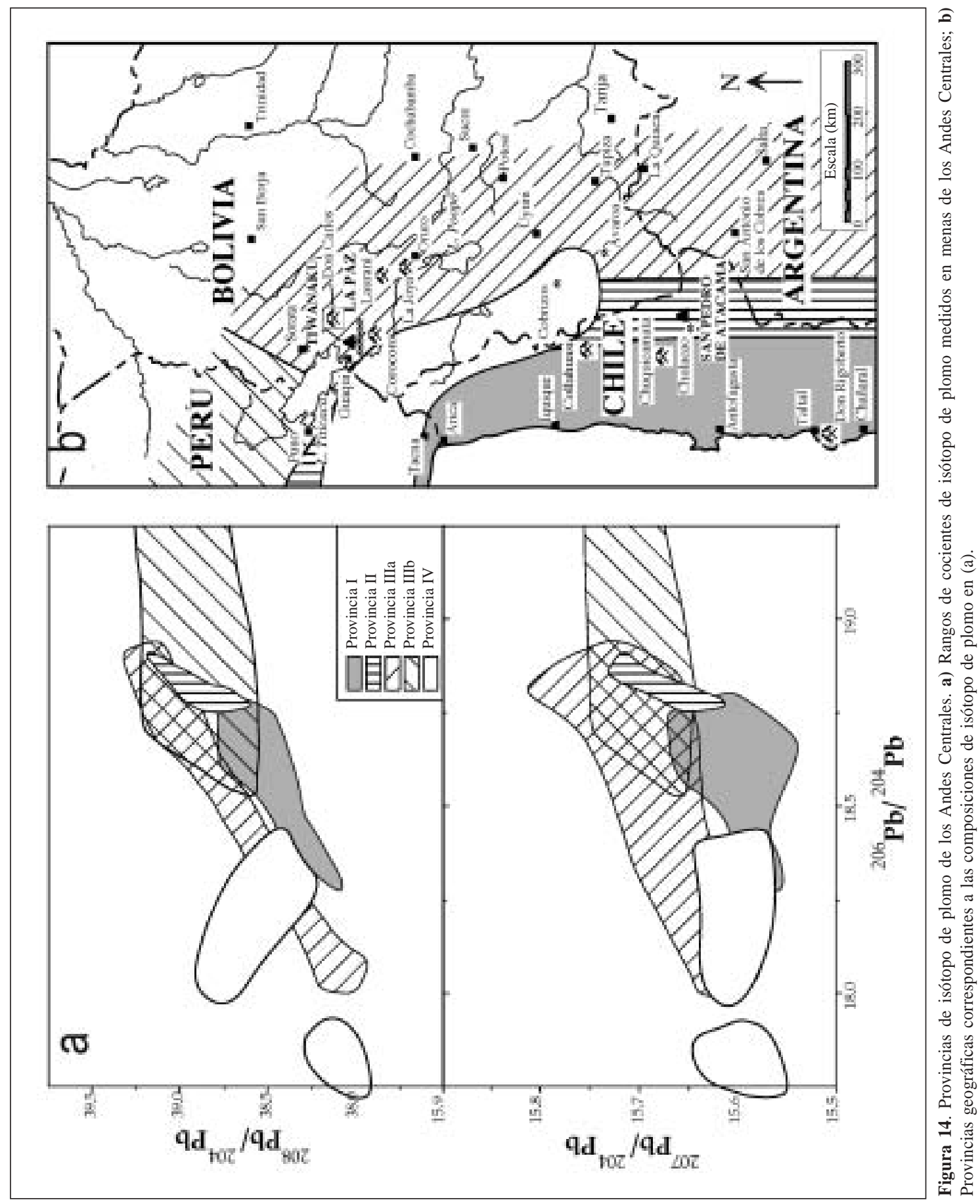




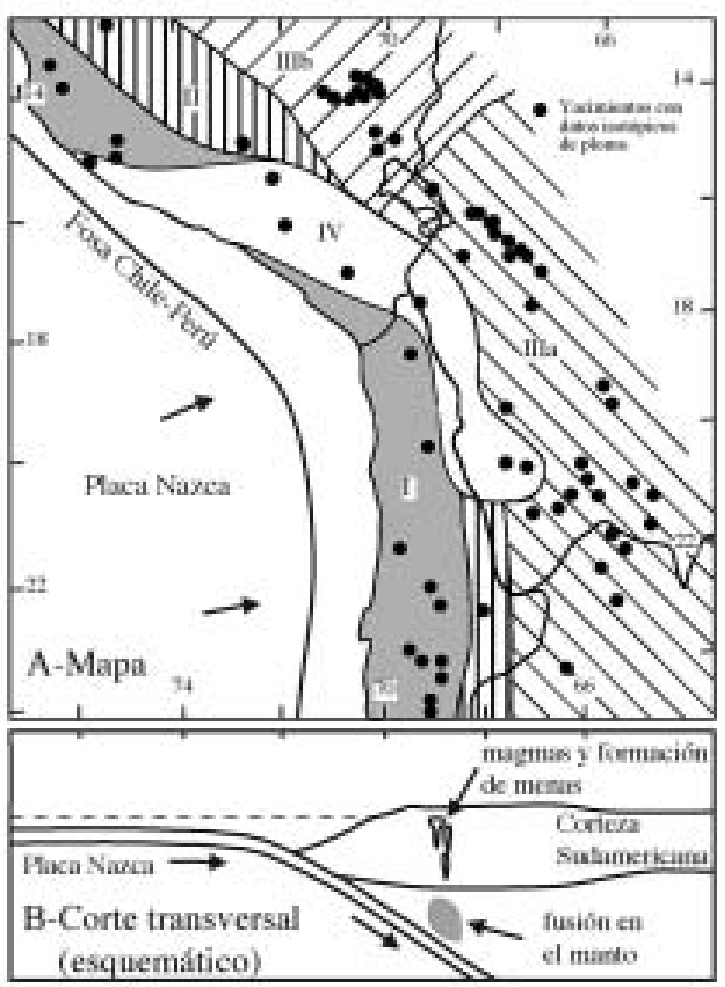

Figura 15. Distribución de los depósitos de menas en los Andes centrales y provincias isotópicas en relación con la frontera tectónica entre la placa Sudamericana y la de Nazca. La frontera entre placas está marcada en la superficie por la fosa Chile-Perú que corre aproximadamente paralela a la línea de costa. a) Vista del mapa; b) Sección transversal esquemática (la geometría exacta varía con la latitud).

del borde occidental de Sudamérica. Los magmas resultantes se han levantado abriéndose paso y han interactuado con la corteza continental superpuesta, produciendo una larga historia de actividad volcánica y la producción de menas asociadas.

El control de la formación de menas por subducción a lo largo de la Fosa Chile-Perú ha producido importantes variaciones en los cocientes del isótopo de plomo en las menas andinas. Los cocientes del isótopo de plomo varían con las distancia desde la fosa y varían también a causa de las diferencias en la geología de la corteza sudamericana. En general, estas variaciones isotópicas reflejan la creciente predominancia del plomo en la corteza continental sudamericana con la creciente distancia desde la Fosa Chile-Perú.
Se ve claramente que las provincias isotópicas corren en un sentido paralelo a la Fosa Chile-Perú. Las firmas isotópicas cambian de oeste a este, desde la Provincia Isotópica I a la Provincia Isotópica III, de acuerdo con la distancia entre el terreno y la fosa. Notamos en la Figura 14b que las grandes minas de Chuquicamata y de Collahuasi están ubicadas en una zona geográfica que corresponde a la Provincia Isotópica I (la zona denominada "costa"), aunque Collahuasi se sitúa a unos $5000 \mathrm{~m}$ de altura y Chuquicamata a unos $2600 \mathrm{~m} . \mathrm{snm}$. No es la altura del depósito lo que determina su firma isotópica, sino la distancia de la fosa.

En la Figura 14 el mapa está acompañado por un grupo de gráficos isotópicos (Figura 14a) indicando la forma y extensión de los campos isotópicos de plomo de cada provincia, campos que ya han sido determinados para rocas y menas de la región (Macfarlane et al. 1990; Kamenov et al. 2002). Por ejemplo, el mapa indica que la mina Chuquicamata está ubicada en la costa desértica del norte de Chile. Se supone que los valores isotópicos de plomo analizados de las menas de Chuquicamata caerían dentro del campo de la Provincia I del gráfico mostrado en la Figura 14a. De igual manera, el mapa muestra que la mina Corocoro está ubicada en el altiplano del norte de Bolivia. Se supone que los valores isotópicos de plomo analizados de las menas de Corocoro caerían dentro del campo de la Provincia III de la Figura 14a.

Notamos que las provincias isotópicas que representan menas de la costa (Provincia I) y menas del altiplano y de la sierra alta (Provincia III) toman una orientación casi horizontal, mientras que el campo que representa menas de las yungas o vertientes occidentales (Provincia II) toma una orientación casi vertical. Esta situación surgió durante la formación de la capa exterior de la tierra. Cuando las rocas y menas en la región de la Provincia II se formaban originalmente en la capa exterior, los procesos volcánicos causaron una mezcla geológica de los materiales provenientes de las Provincias I y III. Los valores isotópicos de las rocas y menas de la Provincia II reflejan esta mezcla geológica. Como resultado el campo isotópico de la Provincia II siempre se presenta muy inclinado y muy angosto. 


\section{Resultados de los análisis isotópicos de plomo: Menas y artefactos asociados con Tiwanaku y San Pedro de Atacama}

Durante varios reconocimientos geológicos en la región entre el lago Titicaca y el Noroeste Argentino (Figura 16; Lechtman 2003a), muestreamos menas de depósitos de cobre y de cobre ricos en arsénico para sus análisis isotópicos de plomo. Las Figuras 17 a 21 indican algunos de nuestros resultados. La Figura 17 presenta los análisis isotópicos de plomo de tres minas chilenas de la costa y de las vertientes occidentales norteñas. Los valores isotópicos de plomo analizados de las ricas menas arsenicales de Chuquicamata caen totalmente dentro del campo de la Provincia I, el campo determinado por las menas costeñas. Los análisis hechos recientemente indican que los valores isotópicos de plomo de las menas de cobre de Collahuasi también caen dentro del campo de la Provincia I. Las firmas isotópicas de cada mina forman una agrupación estrecha y las dos agrupaciones están casi superpuestas. Casi no podemos diferenciar las firmas isotópicas de plomo de Chuquicamata de las de Collahuasi, pero es evidente que las firmas isotópicas de plomo de estas dos grandes minas caen en la Provincia I.

Por otra parte, los valores isotópicos de plomo analizados del depósito de Chulacao, una mina de cobre muy cercana al actual pueblo de San Pedro de Atacama, caen totalmente dentro de un campo de la Provincia II, con su característica formación inclinada. La ubicación en el gráfico de cualquier campo de la Provincia II puede ser trasladada por el eje horizontal del gráfico, desde la izquierda a la derecha, pero cada campo siempre mantiene la forma pendiente y angosta.

La Figura 18 presenta los resultados de nuestros análisis isotópicos de plomo de las menas provenientes de un grupo de minas ubicadas cerca de Tiwanaku y de dos vetas de la mina Corocoro ubicada más lejos, hacia el suroeste. Todos los valores de los isótopos de plomo determinados de estas menas altiplánicas caen totalmente dentro del campo de la Provincia III.

Estamos tomando muestras de menas de cobre provenientes de la zona de Lípez, en el extremo sur de Bolivia (Figura 16). Hasta ahora hemos analizado las menas de dos minas de Lípez:

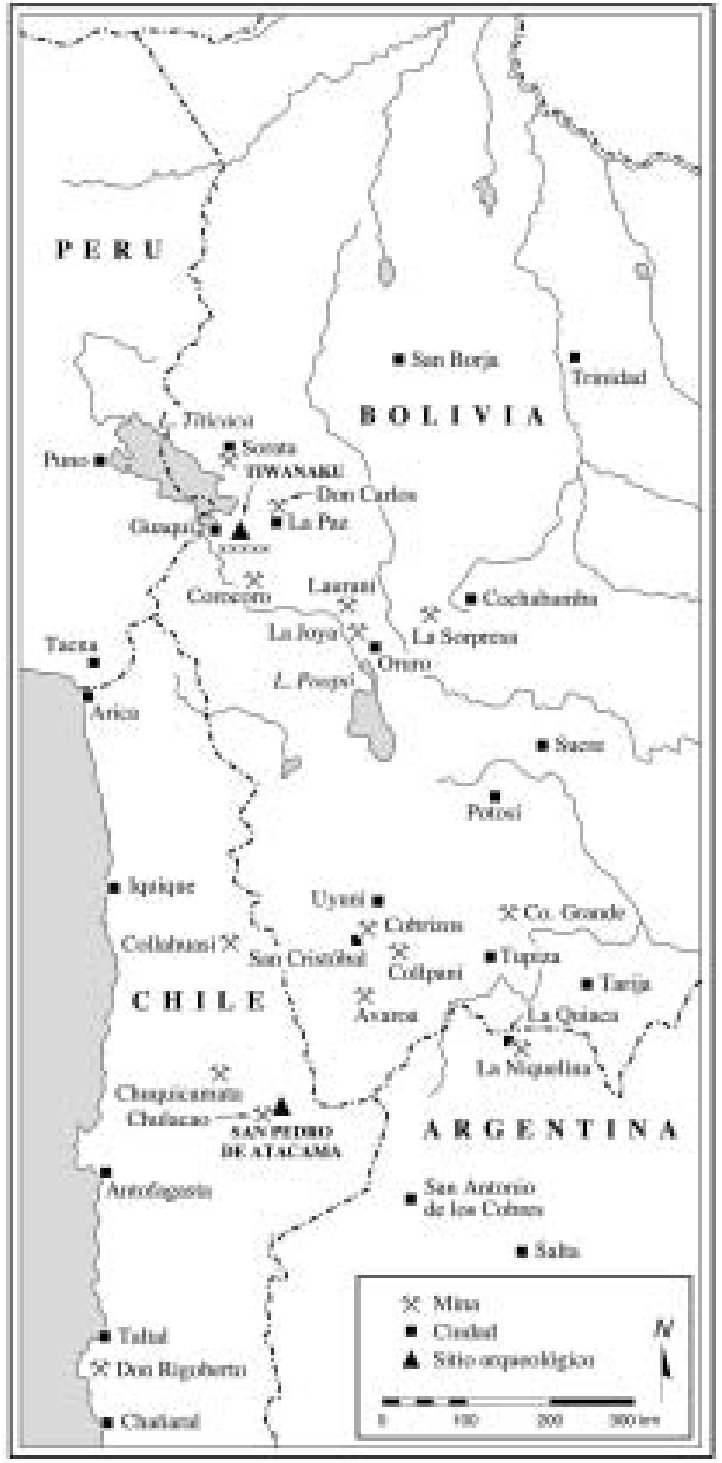

Figura 16. Mapa de la zona andina centro sur, entre Tiwanaku y San Pedro de Atacama. Las minas indicadas han sido incluidas en una investigación para determinar las posibles fuentes de menas explotadas durante el Horizonte Medio (tomado de Lechtman 2003a).

Avaroa y Cobrizos. La mina Avaroa cae en el campo de la Provincia isotópica III; la mina Cobrizos cae en el campo de la Provincia IV (Figura 18). Como las de la Provincia III, las menas de la Provincia IV están dominadas por plomo proveniente de la corteza continental. La Provincia IV difiere de la Provincia III porque la corteza continental debajo de esta área de los Andes tiene una firma isotópica de plomo distintivo, con bajo $206 \mathrm{~Pb} / 204 \mathrm{~Pb}$ en comparación con $208 \mathrm{~Pb} / 204 \mathrm{~Pb}$. 
HEATHER N. LECHTMAN, ANDREW W. MACFARLANE

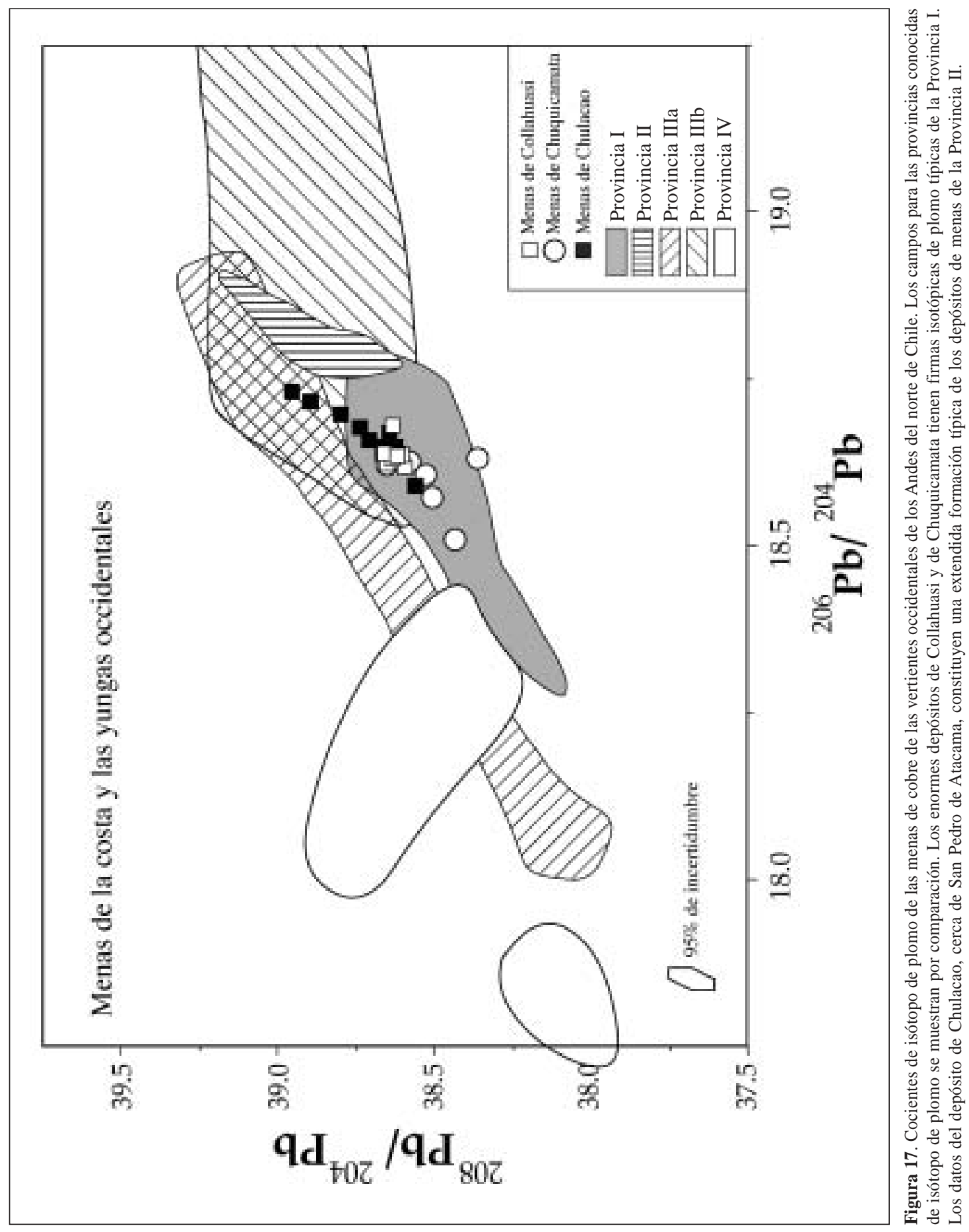


LA METALURGIA DEL BRONCE EN LOS ANDES SUR CENTRALES: TIWANAKU...

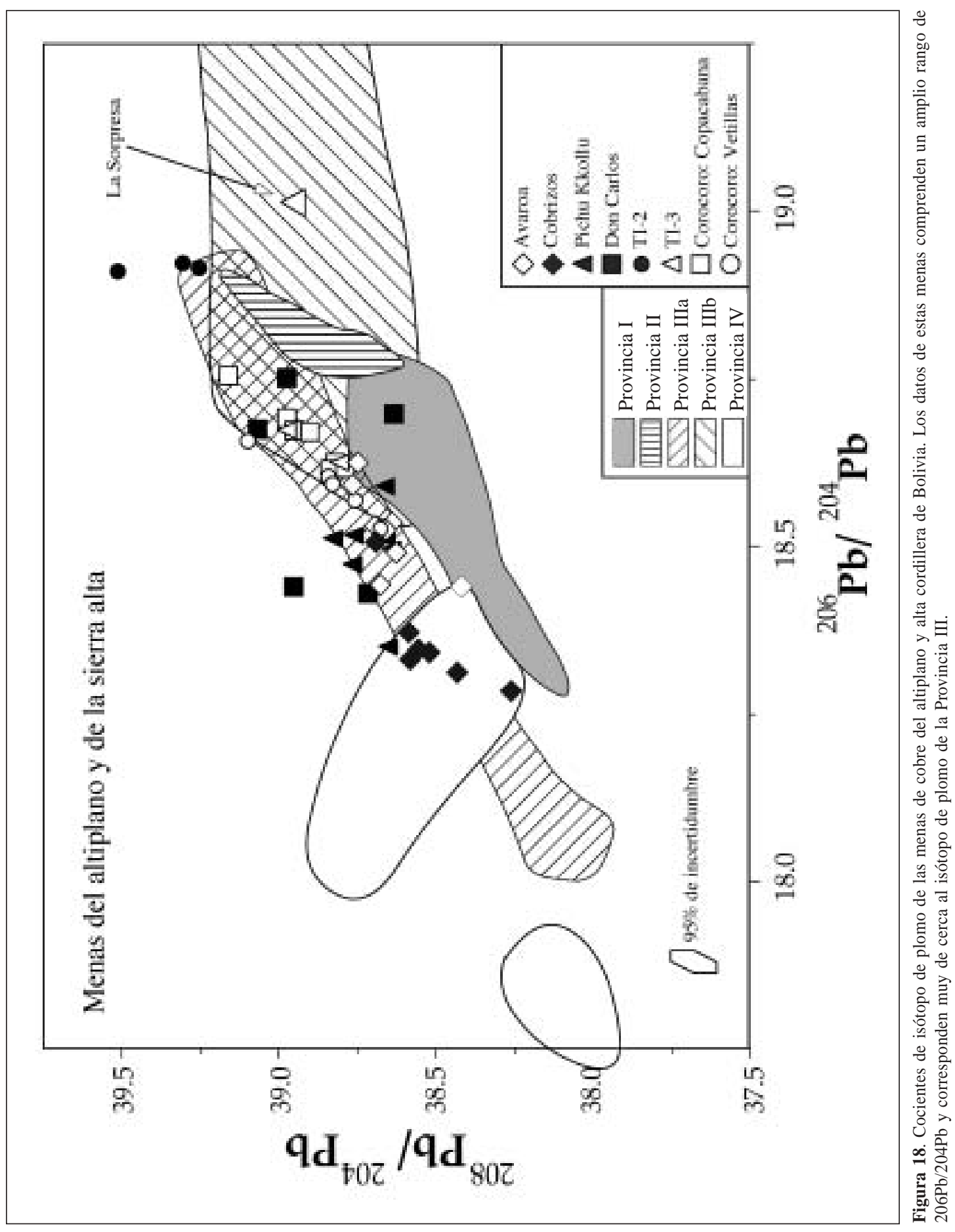


HEATHER N. LECHTMAN, ANDREW W. MACFARLANE

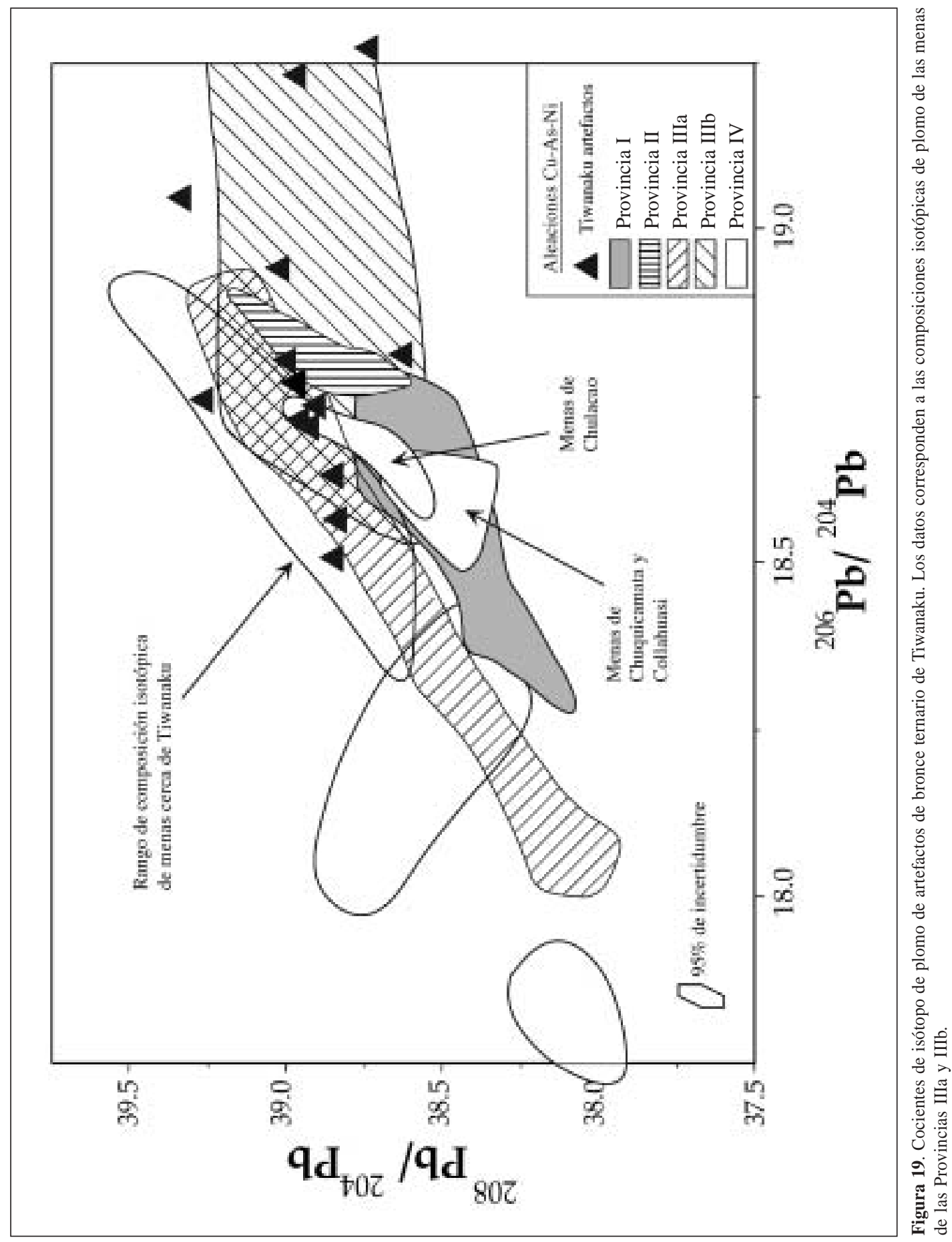


LA METALURGIA DEL BRONCE EN LOS ANDES SUR CENTRALES: TIWANAKU...

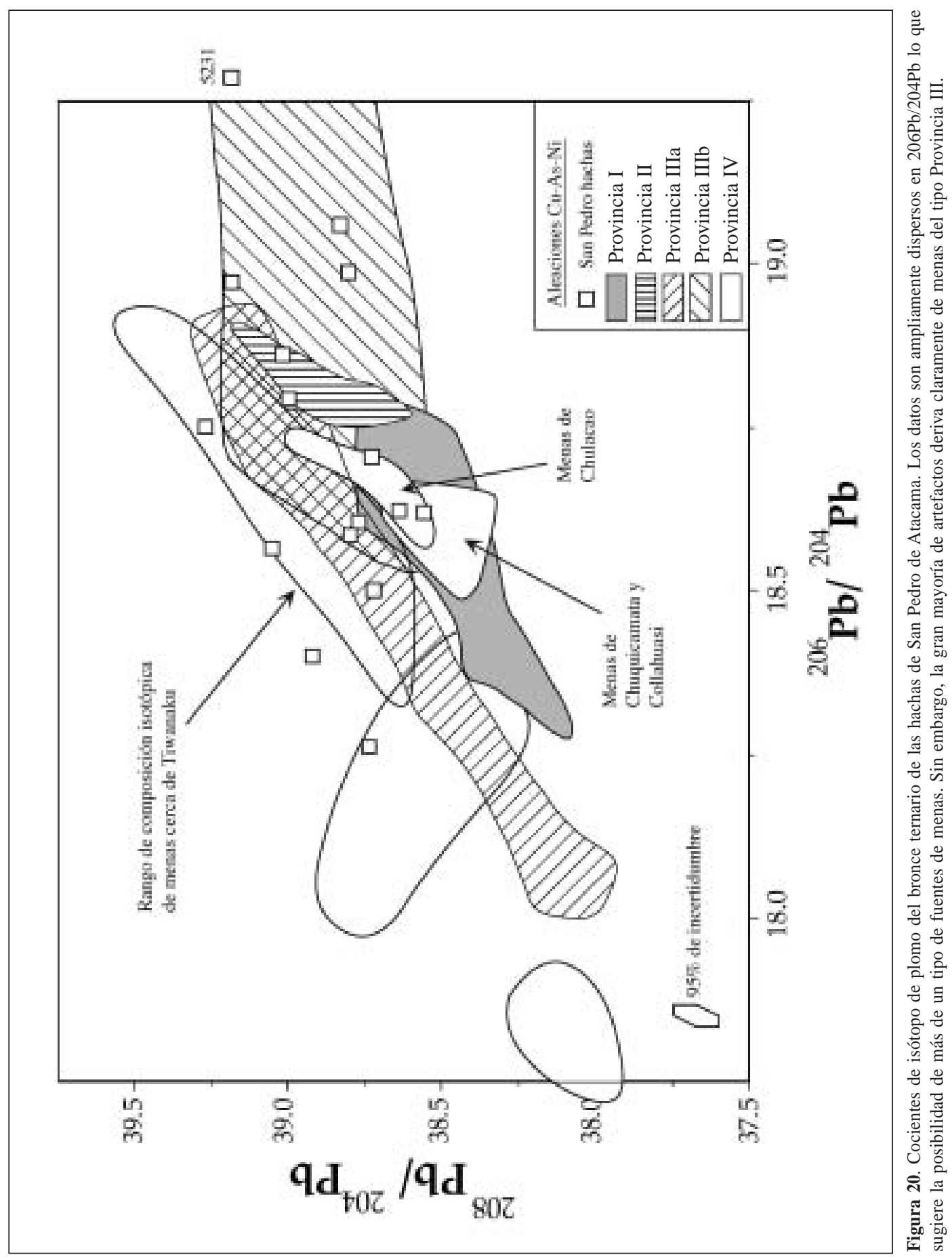


HEATHER N. LECHTMAN, ANDREW W. MACFARLANE

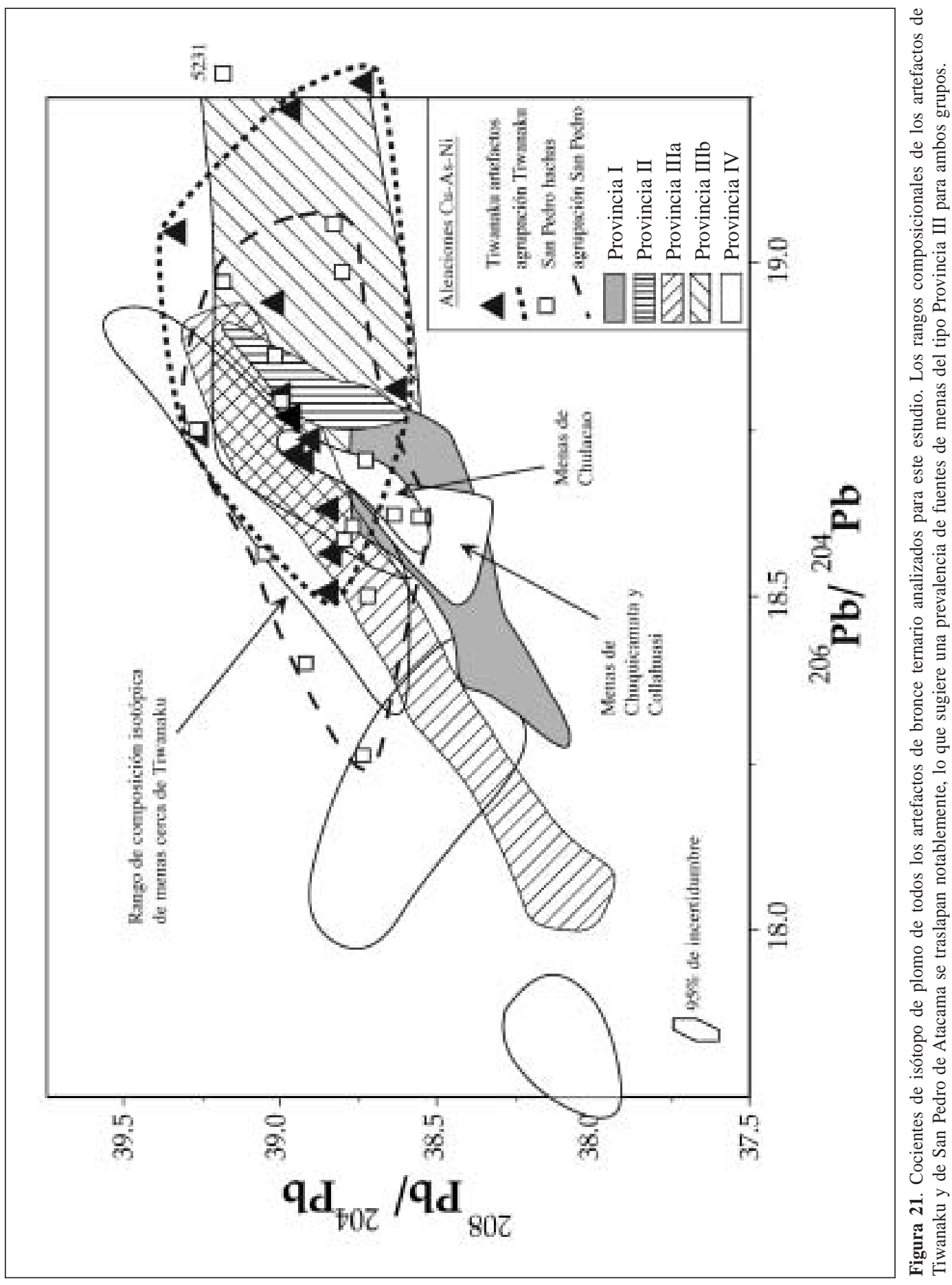


Durante el proceso de la fundición, cuya función es la de extraer de una mena su componente metálico, una parte del plomo en la mena pasa directamente y sin alteración química al metal. El valor isotópico del plomo no cambia durante el proceso de la fundición. Por eso, el valor isotópico del metal fundido es el mismo que el valor isotópico de la mena que le dio origen (Macfarlane 1999). Este hecho permite hacer comparaciones entre las firmas isotópicas de objetos por un lado, y las firmas isotópicas de una mena por el otro, con el fin de determinar si existe una correspondencia entre ambos.

En la Figura 19, superpuestos en los campos de menas del altiplano, hemos indicado los valores isotópicos determinados por 14 artefactos de bronce ternario provenientes de Tiwanaku (la firma isotópica de plomo de cada objeto está indicada con un triangulo negro). En la Figura 20, superpuestos en los campos de menas de la costa, hemos indicado los valores isotópicos determinados por 16 hachas de bronce ternario provenientes de San Pedro de Atacama (la firma isotópica de plomo de cada hacha está indicada con un cuadrado blanco).

\section{Artefactos del área de Tiwanaku}

De los 14 análisis de isótopo que determinamos para los artefactos de bronce $\mathrm{Cu}-\mathrm{As}-\mathrm{Ni}$ provenientes del área de Tiwanaku (Figura 19), sin duda nueve derivan de la Provincia IIIa. Tiwanaku se encuentra geográficamente dentro de la Provincia IIIa y estos análisis tambien están dentro o en el margen de error del campo de análisis de menas del área de Tiwanaku. Incluimos en esta área menas de los depósitos de Corocoro y de Don Carlos (ver Figura 16). Los datos isotópicos son consistentes y los interpretamos como que la mayor parte de los artefactos Tiwanaku fueron hechos a partir de menas obtenidas localmente.

Los restantes cinco análisis de artefactos de Tiwanaku contienen un componente de plomo con un alto cociente de $206 \mathrm{~Pb} / 204 \mathrm{~Pb}$ por lo que están a la derecha del campo de la Provincia IIIa que se muestra en la Figura 19. Estos análisis coinciden con el campo para la Provincia IIIb (Macfarlane et al. 1990; Kontak et al. 1990). Las menas de la Provincia IIIb son dominadas por plomo desde una fuente de corteza continental diferente de aque- llas que caracterizan la Provincia IIIa Geográficamente estas menas ocurren en el área de la cordillera de Carabaya del sureste del Perú, al noroeste del lago Titicaca. Es posible que menas de esta área también fueran utilizadas en Tiwanaku.

\section{Las hachas de San Pedro de Atacama}

Hemos realizado un total de 16 análisis en las hachas de San Pedro de Atacama. De éstas, 13 tienen inequívocamente firmas isotópicas de plomo de tierras altas que derivan de menas de la Provincia IIIa, Provincia IIIb o Provincia IV (Figura 20). Las fuentes dominantes de menas utilizadas en la manufactura de estos artefactos no pueden haber estado en el cinturón de cobre chileno. Entre las menas con firmas isotópicas de plomo del altiplano, la mitad están marcadas en o cerca del campo para la Provincia IIIa o están incluidas dentro del campo de análisis de menas del área de Tiwanaku.

Dentro del grupo de 16 hachas, un grupo más pequeño de análisis (cuatro hachas) está marcado a valores más altos de $206 \mathrm{~Pb} / 204 \mathrm{~Pb}$. Las únicas fuentes de menas que actualmente se sabe son compatibles con estas composiciones isotópicas de plomo están en la Provincia IIIb (sureste del Perú). Es posible que menas con estas firmas isotópicas de plomo puedan ocurrir también en el Noroeste Argentino pero aún disponemos de muy pocos datos isotópicos para esa región.

Dos de los análisis de las 16 hachas de San Pedro muestran cocientes muy bajos de $206 \mathrm{~Pb} / 204 \mathrm{~Pb}$ respecto a $208 \mathrm{~Pb} / 204 \mathrm{~Pb}$. Estos valores de isótopo de plomo están arriba y a la izquierda del conjunto principal de la Provincia IIIa y fuera del rango de las menas del área de Tiwanaku. Los cocientes de isótopo de plomo sugieren que estos dos artefactos podrían contener un componente de la mena de cociente muy bajo $206 \mathrm{~Pb} / 204 \mathrm{~Pb}$ típico de la Provincia IV que ocupa el Lípez y las regiones del altiplano occidental de Bolivia.

Los cocientes de isótopo de plomo de las restantes tres hachas de San Pedro de Atacama están marcados dentro de la Provincia I. Tres de estos análisis son consistentes con las composiciones de menas del cercano depósito de Chulacao, y dos son consistentes con la mena proveniente de Collahuasi o de Chuquicamata. 
Las menas de la Provincia IIIb que se traslapan isotópicamente con la Provincia I (Figuras 14 y 20) son principalmente menas de plomo-zinc-plata $(\mathrm{Pb}-\mathrm{Zn}-\mathrm{Ag})$ con un componente menor de cobre (Kontak et al. 1990). En consecuencia, es poco probable que hayan proporcionado menas fuentes para estos artefactos.

Los cocientes de isótopos de plomo de las hachas de San Pedro de Atacama parecen reflejar un amplio rango geográfico de materiales fuentes, predominantemente de las provincias de tierras altas IIIa y IIIb, con contribuciones menores de las áreas cercanas en Lípez y Chile.

En la Figura 21 hemos combinado los datos de las Figuras 19 y 20 que permite hacer una comparación más directa de los resultados analíticos. El campo descrito por los valores de los objetos de Tiwanaku está indicado por una línea de guiones cortos. El campo formado por las firmas isotópicas de las hachas de San Pedro está encerrado por una línea de guiones largos.

\section{Conclusiones}

Se pueden sacar varias conclusiones de estos resultados analíticos.

Primero, notamos que todos los artefactos de Tiwanaku fabricados con el bronce ternario derivan de menas altiplánicas y de las sierras altas. No había ninguna contribución de alguna mena costeña o de las vertientes occidentales en la producción de estas aleaciones.

Segundo, notamos que las menas provenientes de la gran mina costeña de Chuquicamata no habían sido usadas en la gran mayoría de los casos para producir la aleación ternaria de bronce encontrada en las hachas de San Pedro de Atacama. Concluimos lo mismo respecto a las menas de Collahuasi.

Tercero, notamos que las firmas isotópicas de plomo de las hachas de San Pedro forman una agrupación abierta y con un amplio rango de valores. Las firmas isotópicas de plomo de las hachas caen principalmente dentro de la Provincia III. Esto significa que habría una contribución mayor y significativa de las menas de la Provincia III -es decir, del altiplano- a la producción del bronce ternario encontrado en las hachas. En efecto, se puede decir que las hachas de San Pedro de Atacama fueron hechas con menas provenientes del altiplano.

Hay varias opciones para interpretar este último resultado. Es posible que en San Pedro de Atacama se hallan obtenido menas del altiplano y usado aquellas para fabricar algunas de las hachas. También es posible que en lugar de las menas, en San Pedro, adquirieran lingotes de bronce ternario de las tierras altas, es decir, lingotes fabricados con menas de la sierra. Finalmente, es posible que las firmas isotópicas de plomo de las hachas que caen dentro de la Provincia III representen hachas fabricadas en las tierras altas y exportadas a San Pedro.

Estos resultados obtenidos de las investigaciones isotópicas de plomo ayudan a aclarar cuáles fueron las fuentes de las menas de cobre o de cobre rico en arsénico que habrían sido fundidas para producir el bronce ternario usado para fabricar muchos de los artefactos encontrados en Tiwanaku y en San Pedro de Atacama. Desgraciadamente, los resultados no nos acercan a una determinación de la fuente de níquel usada en estas aleaciones de bronce ternario.

El rango muy amplio de las firmas isotópicas de plomo del tipo Provincia III del bronce ternario de las hachas sugiere que su plomo provino de las numerosas menas de cobre isotópicamente diferentes de la Provincia III, más bien que de un pequeño número de depósitos de níquel. Aparentemente los valores isotópicos de plomo asociados con los minerales de níquel fundido con los minerales de cobre no son lo suficientemente diferentes para producir un efecto detectable en los análisis que hemos hecho; o las concentraciones de plomo en las menas que contienen níquel eran demasiado bajas para influenciar las composiciones isotópicas de aleaciones hechas con menas de la Provincia III que contienen cobre. Por lo tanto, el método de isótopo de plomo no se adapta bien para identificar con confianza la fuente del componente níquel en estas aleaciones ternarias.

Ya que el elemento osmio esta presente en mayores proporciones que el plomo en las rocas que contienen níquel, y porque los cocientes del isótopo de osmio varían mucho en la naturaleza, las mediciones de los cocientes del isótopo de osmio en las aleaciones del bronce ternario podrían ofrecer nuevas restricciones en cuanto a la identifica- 
ción de la fuente del níquel. Por ejemplo, los cocientes del isótopo de osmio tendrían que permitirnos decir si el níquel provino de una fuente de la Provincia I.

Un pequeño número de los objetos analizados de Tiwanaku y San Pedro tienen valores de 206Pb/ $204 \mathrm{~Pb}$ notablemente más altos que cualquiera de las menas bolivianas conocidas de la Provincia III. Estos valores se traslapan con menas de la sección peruana de la Provincia III muchas de las cuales ocurren en el lejano sureste del Perú (Provincia IIIb en la Figura 14a). Es posible que estos bronces se hicieran con cobre del sureste del Perú. Sin embargo, también hay varios depósitos de cobre conocidos en el Noroeste Argentino que geográficamente están mucho más cerca de San Pedro y que se esperaría contengan plomo del tipo Provincia III. Nuevos análisis de tales menas del noroeste de Argentina deberían indicar si estas menas podrían haber proporcionado el cobre para algunas de las aleaciones ternarias utilizadas para producir los artefactos hallados en Tiwanaku y en San Pedro de Atacama.

Esta investigación es un trabajo que va a continuar, ya que tenemos que hacer el mismo tipo de estudio para las menas del Noroeste Argentino y para artefactos de bronce estañífero provenientes de la zona centro-sur.

Agradecimientos Los exámenes y análisis de los artefactos arqueológicos de Bolivia y Chile fueron realizados con permisos concedidos por las autoridades de ambos países. En La Paz la investigación fue aprobada por la Secretaría Nacional de Cultura, Ministerio de Desarrollo Humano, con Resolución Secretarial no 039/95 (5 de junio de 1995). En San Pedro de Atacama la investigación fue aprobada por el Director del Instituto de Investigaciones Arqueológicas y Museo de la Universidad Católica del Norte, para el período comprendido entre los años 1998 y 2001. En 1996 y 1998 Heather Lechtman recibió de la Curtiss T. Brennan \& Mary G. Brennan Foundation dos becas para la realización del trabajo de campo. En Bolivia y Chile este trabajo se hizo mucho más fácil por la asistencia proporcionada por David Cadwell durante sus años como Gerente General de la Compañía Minera Asarco, S. A., Iquique, Chile. Heather Lechtman agradece a Myriam Tarragó y a Agustín Llagostera su ayuda en la determinación de la cronología relativa de las hachas de San Pedro. Los autores agradecen a Ana María Soldi por su traducción al español del manuscrito.

\section{REFERENCIAS CITADAS}

KAMENOV, G., A. W. MACFARLANE y L. RICIPUTI, 2002. Sources of lead in the San Cristóbal, Pulacayo, and Potosí mining districts, Bolivia, and a reevaluation of regional ore lead isotope provinces. Economic Geology 97: 573-592.

KONTAK, D. J., G. L. CUMMING, D. KRSTIC, A. H. CLARK y E. FARRAR, 1990. Isotopic composition of lead in ore deposits of the Cordillera Oriental, southeastern Peru. Economic Geology 85: 1584-1603.

LECHTMAN, H., 1996. Arsenic bronze: Dirty copper or chosen alloy? Journal of Field Archaeology 23: 477-514.

1997. El bronce arsenical y el Horizonte Medio. En Arqueología, antropología e historia en los Andes: Homenaje a María Rostworowski, R. Varón y J. Flores E. (Eds.), pp. 153-186. Instituto de Estudios Peruanos, Lima.

1998. Architectural cramps at Tiwanaku: Copper-arsenicnickel bronze. En Metallurgica Antiqua, T. Rehren, A. Hauptmann y J. Muhly, (Eds), Der Anschnitt 8: 77-92. Bergbau-Museum, Bochum.
1999. El bronce y el Horizonte Medio. Boletín Museo del Oro 41: 2-25.

-2003a. Tiwanaku Period (Middle Horizon) bronze metallurgy in the lake Titicaca basin: A preliminary assessment. En Tiwanaku and its hinterland, T 2. A. Kolata, (Ed.), pp. 404-434. Smithsonian Institution Press, Washington D. C.

2003b. Middle Horizon bronze: Centers and outliers. En Patterns and process, L. van Zelst, (Ed.), pp. 248-268. Smithsonian Center for Materials Research and Education, Washington D. C.

MACFARLANE, A. W., 1999. The lead isotope method for tracing the sources of metal in archaeological artifacts: Strengths, weaknesses and applications in the Western Hemisphere. En Metals in Antiquity, S. M. Young, A. M. Pollard, P. Budd y R. A. Ixer, (Eds.), BAR International Series 792: 310-316. Archaeopress, Oxford.

MACFARLANE, A. W., P. MARCET, A. P. LEHURAY y U. PETERSEN 1990. Lead isotopic provinces of the central Andes inferred from ores and crustal rocks. Economic Geology 85: 1857-1880. 